\title{
Mesoporous Materials as Supports of Active Molecules: A Versatile Strategy of Functionalization of Inorganic Oxides
}

\author{
Vanina A Guntero ${ }^{1}$, Cristián A Ferretti ${ }^{1}$, Pedro ME Mancini ${ }^{1}$ and María N Kneeteman*2 \\ ${ }^{1}$ Laboratorio Fester - Organic Chemistry (FIQ), Department of Chemistry (FIQ), National University of the Litoral (UNL),(IQAL) \\ Institute of Chemistry of the Litoral, Argentina \\ ${ }^{2}$ Faculty of Chemical Engineering (FIQ), IQAL (Institute of Chemistry of the Litoral) (CONICET-UNL), Department of Chemistry (FIQ), \\ National University of the Litoral (UNL), (IQAL) Institute of Chemistry of the Litoral, Argentina \\ *Corresponding author: María N Kneeteman, Faculty of Chemical Engineering (FIQ), Department of Chemistry (FIQ), National \\ University of the Litoral (UNL), IQAL (Institute of Chemistry of the Litoral) (CONICET-UNL), Argentina
}

\section{ARTICLE INFO}

Received: 慧 February 21, 2019

Published: 慧 March 01, 2019

Citation: Vanina A Guntero, Cristián A Ferretti, Pedro ME Mancini, María N Kneeteman. Mesoporous Materials as Supports of Active Molecules: A Versatile Strategy Of Functionalization of Inorganic Oxides. Biomed J Sci \& Tech Res 15(3)-2019. BJSTR. MS.ID.002699.

\begin{abstract}
Ordered mesoporous silica and alumina were functionalized with vanillin, eugenol and their bis-compounds through a microwave assisted process. The physicochemical characterization of these materials confirmed the successful immobilization of these molecules onto the surface of these oxides, keeping the ordered mesopore structure of supports and the antioxidant activity of molecules. The results suggest the possibility of applying these materials as a new component of the packaging of aliment or cosmetic with antioxidant properties in the future.
\end{abstract}

Keywords: Mesoporous Materials; Active Molecules; Functionalization

Abbreviations: XRD: X-ray Diffraction; RMN: Magnetic Resonance Nuclear; TEM: High Resolution Transmission Electron Microscopy; XPS: X-ray Photoelectron Spectroscopy; FTIR: Fourier Transformation Infrared Spectroscopy; BHT: Butylhydroxytoluene; AM: Active Molecules; MD: Molecular Diameter; SAXS: Small Angle XRD

\section{Introduction}

Mesoporous oxides, such as silica and alumina, are a suitable inorganic support due to its uniform wide channels that can immobilize organic molecules with chemistry activity. Its stability leads to better dispersion, biocompatibility and subsequent functionalization [1,2]. On the other hands, natural products as vanillin and eugenol compound are important sources to design new molecules, featuring unique modes of action, low toxicity, easy decomposition, environmental friendliness and desirable biological activities. In addition, vanillin and eugenol derivatives possess desirable antifungal, antibacterial and antioxidant activities [3]. However, a few studies on the application of these compound derivatives have been reported. Considering the potent antioxidant activity of eugenol and vanillin compounds, in the present work, vanillin, eugenol and their bis-compounds were synthesized and then supported in mesoporous silica and alumina. In particular, the focus was on the supporting of these active molecules into mesoporous oxides and on the evaluation of the antioxidant activity of these novel systems.

\section{Experimental}

\section{Synthesis}

The active molecules, eugenol, vanillin, 5,5'-bis-eugenol [4] and 5,5'-bis-vanillin [5], were synthetized as was reported in the respective references. Mesoporous oxides selected as inorganic support were silica and alumina which were prepared according to the bibliography [6,7]. The supporting of active molecules (9 wt \%) on mesoporous silica and alumina were performed by a microwaveassisted oven procedure [8].

\section{Characterization of Materials}

Several techniques were employed to characterize the properties and structure of materials. They include N2 physisorption, wide 
and small angle X-ray diffraction (XRD), magnetic resonance nuclear (RMN), high resolution transmission electron microscopy (TEM), X-ray photoelectron spectroscopy (XPS) and Fourier transformation infrared spectroscopy (FTIR). Antioxidant activity of materials was determined using phosphomolybdenum method [8] and compared with butylhydroxytoluene (BHT) antioxidant and free active molecules.

\section{Results and Discussion}

All the active molecules (AM) were checked by melting points and spectroscopic studies (IR, 1H-NMR, 13C-NMR). The physical and spectral data confirmed the structures and purity of the compounds. From the geometrical structures of molecules optimized by DFT tools were obtained the molecular diameter (MD) values. The values were 6-8 $\AA$ for 1-2 molecules and 11-14 for 3-4 molecules. $\mathrm{N}_{2}$ adsorption/desorption isotherms of materials were determined in order to study their textural properties and results are reported in Table 1. All samples show $\mathrm{N}_{2}$ adsorption/ desorption curves corresponding to type IV isotherms as isotherms showed in Figure 1-up [9]. Considering the values of MD calculated of MA, it is possible to understand that these molecules can be easily located within the pores of these oxides. The embedding of MA into silica and alumina caused a reduction of specific surface area and the pore volume. The values of average pore diameter changed by the incorporation of MA on these material without modify the mesoporosity of materials [10]. The small-angle XRD (SAXS) patterns indicate the presence of uniform mesoporosity. As can be seen in Figure 1-down, the SAXS patterns for the samples exhibit characteristic peaks at $2 \otimes$ between $0.5^{\circ}$ and $2.0^{\circ}$, indicating the presence of uniform mesoporous, which can be ordered or wormlike [11]. For the samples with MA, the present of these compound on oxides gives rise to a decrease in the diffracted intensity (Figure 1), likely attributed to the reduction of scattering contrast ascribed to the presence of the loaded molecules. TEM micrograph images, (Figure 2) clearly showed that these materials exhibit a regular worm-like channel motif and ordered structures. The packing of the cannel system is more or less random, as was reported by other authors [12,13].
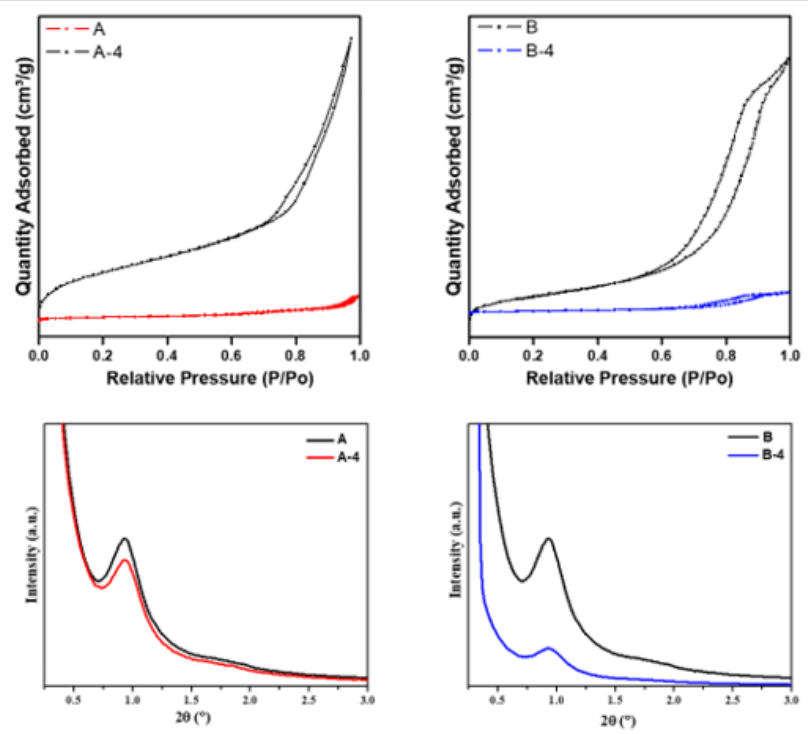

Figure 1: (up) Nitrogen adsorption/desorption isotherms and (down) Small-angle X-ray scattering patterns of the silica and alumina materials $₫ \mathrm{~A}$ : Silica; B: Alumina; 1: vanillin; 2: eugenol; 3: bis-vanillin; 4: bis-eugenol冈.

Table 1: Textural parameters of materials.

\begin{tabular}{|c|c|c|c|}
\hline Sample & Specific Surface Area (m²/g) & Pore Volume $\left(\mathrm{cm}^{2} / \mathrm{g}\right)$ & Average Pore Diameter (Å) \\
\hline A & 578 & 1.68 & 116 \\
\hline A-1 & 405 & 0.90 & 90 \\
\hline A-2 & 418 & 0.92 & 87 \\
\hline$A-3$ & 264 & 0.61 & 92 \\
\hline A-4 & 387 & 0.78 & 83 \\
\hline B & 266 & 0.90 & 136 \\
\hline B-1 & 172 & 0.75 & 174 \\
\hline B-2 & 164 & 0.72 & 178 \\
\hline B-3 & 134 & 0.46 & 137 \\
\hline B-4 & 157 & 0.54 & 158 \\
\hline
\end{tabular}


Note: $₫$ A: Silica; B: Alumina; 1: vanillin; 2: eugenol; 3: bis-vanillin; 4: bis-eugenol区
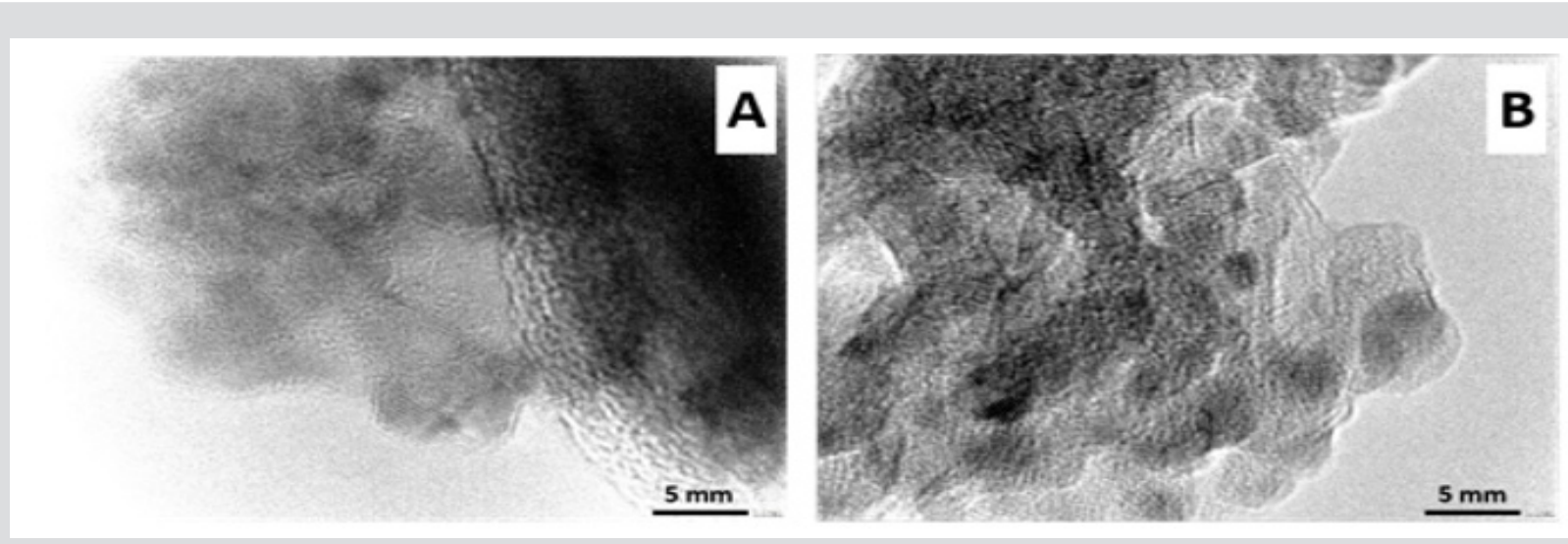

Figure 2: TEM images of A) A-4 and B) B-4 materials, $\triangle A$ : Silica; B: Alumina; 1: vanillin; 2: eugenol; 3: bis-vanillin; 4: biseugenol邓.

The analysis of FTIR spectra of materials indicating the strong interaction between MA present into pores of mesoporous oxides with surface hydroxyl groups of silica and alumina, respectively. Furthermore, XPS spectra alto provide evidence of this electrostatic interaction. To evaluate of synthetized materials as materials with antioxidant activity, was used the phosphomolybdenum method. Silica and alumina showed no antioxidant activity. On the other hand, the other samples presented antioxidant properties. Regardless of the concentration of the free compound, antioxidant potency decreased in the order: BHT $>3-4>1-2$. The inhibitory effect of dimerized vanillin and eugenol are higher than that of monomeric molecules [1]. Active molecules embedding in mesoporous oxides presented higher antioxidant activity than that of free molecules. This was attributed to the increase in the solubility of MA in the molecule-soport system, as a result of their interaction with mesoporous oxides. Results suggest weak interactions of electrostatic nature (hydrogen bond) that connect actives molecules with $\mathrm{OH}$ groups present on the wall of silica or alumina. These interactions do not cause chemical changes in antioxidant property of molecules supported.

\section{Conclusion}

In summary, we had design new systems with ordered structure in which active molecules with antioxidant properties, which were functionalized on surface of mesoporous silica and alumina. The most important characteristic of these materials is the possibility of enhancement the antioxidant activity of the molecules embedding into mesoporous oxides. These findings give an important insight into these ordered mesoporous systems in the development of new antioxidant of packaging in the future.

\section{Acknowledgement}

Authors thank the ANCyT of Argentina, PICT 2014 No. 1587 and CAI+D 2017 of the UNL, Santa Fe, Argentina.

\section{References}

1. Z Tao (2014) Mesoporous silica-based nanodevices for biological applications. RSC Adv 4: 18961-18980.

2. H Akhter, J Murshed, MA Rashed, Y Oshima, Y Nagao, et al. (2017) Fabrication of hydrazine sensor based on silica-coated $\mathrm{Fe}_{2} \mathrm{O}_{3}$ magnetic nanoparticles prepared by a rapid microwave irradiation method. J Alloys Compd 698: 921-929.

3. MI Quindt, LG Gutierrez, MN Kneeteman, PME Mancini, M Parra, et al. (2017) A new highly selective chromogenic and fluorogenic chemosensor for Copper (II). Lett Org Chem 15(8): 659-664.

4. Farias Dias (1988) An improved high yield synthesis of dehydrodieugenol. Phytochem Lett 27(9): 3008-3009.

5. VA Guntero, D Espinoza Martinez, CA Ferreti, PME Mancini (2017) Microwave-assisted embedding of bis-vanillin and bis-eugenol into SBA15: Synthesis of chemosensors precursors for the detection of metal cations. MDPI AG in The $21^{\text {st }}$ International Electronic Conference on Synthetic Organic Chemistry.

6. A Wang, Y Ji, H Yin, S Liu (2016) Synthesis of different-sized SBA15 nanoparticles and their fluoride release performances from poly(methylmethacrylate) dental restorative resin. New J Chem 40: 9781-9787.

7. F Vaundry, S Khodabandeh, ME Davis (1996) Synthesis of Pure Alumina Mesoporous Materials Chem Mater 8(7): 1451-1464.

8. VA Guntero, CA Ferretti, PME Mancini, MN Kneeteman (2018) Encapsulation of compounds biphenyls into SBA-15: Synthesis of composities for application. Glob J Eng Sci Res 5: 32-39.

9. S Song, K Hidajat, S Kawi (2005) Functionalized SBA-15 Materials as Carriers for Controlled Drug Delivery: Influence of Surface Properties on Matrix - Drug Interactions. Langmuir 21(21): 9568-9575.

10. M Stanzione, N Gargiulo, D Caputo, B Liguori, P Cerruti, et al. (2017) Peculiarities of vanillin release from amino-functionalized mesoporous silica embedded into biodegradable composites. Eur Polym J 89: 88-100.

11.K Niesz, P Yang, GA Somorjai (2005) Sol-gel synthesis of ordered mesoporous alumina. Chem Commun 15: 1986-1987.

12. M Ogata, M Hoshi, U Shiro, E Toyoshige (2000) Antioxidant Activity of Eugenol and Related Monomeric and Dimeric Compounds. Chem Pharm Bull 48(10): 1467-1469.

13. J Cejka (2003) Organized mesoporous alumina: synthesis, structure and potential in catalysis Appl Catal A 254(2): 327-338. 
14. J Cejka (2003) Organized mesoporous alumina: synthesis, structure and potential in catalysis Appl Catal A 254(2): 327-338.

\section{ISSN: 2574-1241}

DOI: 10.26717/BJSTR.2019.15.002699

María N Kneeteman. Biomed J Sci \& Tech Res

(C) (P) This work is licensed under Creative

Submission Link: https://biomedres.us/submit-manuscript.php

$\begin{array}{ll}\text { BIOMEDICAL } & \text { Assets of Publishing with us } \\ \text { RESEARCHES } & \text { - Global archiving of articles } \\ & \text { - Immediate, unrestricted online access } \\ \end{array}$

